\title{
On-Line Monitoring and Fault Diagnosis of Box Transformer Substation Based on VPRS- RBFNN
}

\author{
Erbao XU*, Yan LI, Mingshun YANG, Renhao XIAO, Hairui LIN, Xinqin GAO
}

\begin{abstract}
Box transformer substation (BTS) is an important power distribution environment. To ensure the safe and stable operation of the power distribution system, it is critical to monitor the BTS operation and diagnose its faults in a reliable manner. In the Internet of Things (IoT) environment, this paper aims to develop a real-time and accurate online strategy for BTS monitoring and fault diagnosis. The framework of our strategy was constructed based on the loT technique, including a sensing layer, a network layer and an application layer. On this basis, a BTS fault diagnosis method was established with variable precision rough set (VPRS) as the pre-network and the radial basis function neural network (RBFNN) as the back-fed network. The VPRS and the RBFNN were selected, because the BTS faults have many characteristic parameters, with complex nonlinear relationship with fault modes. Finally, a prototype of our strategy was developed and applied to the fault diagnosis of an actual BTS. The results fully demonstrate the effectiveness and feasibility of our strategy.
\end{abstract}

Keywords: box transformer substation (BTS); radial basis function neural network (RBFNN); the Internet of Things (IOT); variable precision rough set (VPRS)

\section{INTRODUCTION}

As the world's largest power generation, the most complex power system, China's power system contains power generation, transmission and transformation, distribution, power consumption and dispatching [1]. As a key link connecting power transmission and users, the safe and reliable operation of distribution network is of great significance to the stability of power system and users' lives and properties. Therefore, it is an urgent task to comprehensively improve the information and automation level of the distribution network, enhance the ability of analysis, early warning and disaster prevention of power distribution links, realize the real-time perception and fine control of the operation status of the power distribution network [2-5].

Domestic and foreign scholars have done a lot of research work on transformer fault diagnosis. Hu et al. [6] mined the casing data of oil-immersed transformers and used Apriori algorithm and Tanimoto coefficient to evaluate the relationship between state parameters; based on Pearson correlation coefficient, the fault diagnosis matrix was constructed, which judges the fault diagnosis mode of the equipment. Feng et al. [7] used the method of data fusion to establish the equipment diagnosis model of power transformer, which reduced the uncertainty of fault diagnosis; Lin et al. [8] found the discrete model of topology structure and state of power system of transformer from a large number of historical data, and proved the synchronous fault principle of transformer. In order to overcome the limitations of DGA method, AbuSiada and Hmood [9] introduced fuzzy logic to identify transformer faults more accurately. Velásquez and Lara [10] designed an adaptive decision system based on principal component analysis and fuzzy logic to realize early fault diagnosis of transformer and obtain degradation rate and health index. Malik and Jarial [11] used fuzzy logic to evaluate four state conditions of transformer deterioration, and evaluated the quality of transformer. The edge paper degradation was estimated and appropriate maintenance scheme was proposed. Chen et al. [12] used rough set to reduce the fault decision table and establish the fault diagnosis rules and decision table of transformer; $\mathrm{Li}$
Hui et al. [13] transformed the characteristic value of the gas in the transformer into two-dimensional data and input it into the convolutional neural network for optimization. In order to calculate the health index of transformer, Mominul et al. [14] proposed a generalized regression neural network GRNN for the state evaluation of transformer.

In the troubleshooting of other power distribution equipment, domestic and foreign scholars have also achieved some research results. Wang et al. [15] proposed a grid fault tracking method based on big data platform to find faulty components and give the cause of faults; Mansour et al. [16] used the Petri net to establish a fault diagnosis model for the fault items of a large power station, so that the monitoring personnel could accurately diagnose the fault. Based on cloud-IoT technology, Meloni et al. [17] proposed SE architecture solution to support the effective evaluation of the distribution network. The results of some studies have shown that online monitoring of power distribution equipment is more reliable with the support of IoT technology [18-20].

To sum up, the research on fault diagnosis of power system is booming, and most of these researches focus on fault diagnosis of power transmission and transformation, and the fault diagnosis of oil immersed power transformer is the core. However, with the continuous development of the Internet of things technology, ubiquitous sensors enable us to master the operation status of distribution equipment more comprehensively. Therefore, it is urgent to use the perspective of big data for intelligent real-time diagnosis of distribution equipment.

The BTS is an important power distribution equipment in the distribution network, which transforms electric energy from high-voltage system above $10 \mathrm{kV}$ to lowvoltage system. Most of the BTS are installed outdoors, the working environment is changeable, the conditions are complicated, and natural disasters and external forces are seriously damaged. In the long-term operation process, various failure problems will occur. When a fault occurs, relying on the manual troubleshooting method, the workload is large, the accuracy is low, and the fault diagnosis state of the BTS cannot be diagnosed and 
processed in real time, which may cause major safety accidents such as large-scale blackouts and explosions.

Therefore, we propose a real-time monitoring and fault diagnosis strategy based on variable precision rough setradial basis function neural network (VPRS-RBFNN) algorithm in the IoT environment. Firstly, a real-time online monitoring platform for BTS equipment based on IoT technology is constructed to realize real-time monitoring of the operation information of the BTS. Secondly, based on the historical data and real-time data of the BTS operation, a fault diagnosis model based on VPRS-RBFNN algorithm is constructed. Finally, the validity and feasibility of the proposed strategy are verified by the specific project of the BTS production enterprise.

\section{OVERVIEW OF THE PROPOSED APPROACH}

The box transformer usually consists of high-voltage equipment, transformer and low-voltage equipment [21], and its structure is shown in Fig. 1. In the actual operation process, the BTS's operation state is affected by many factors, excessive humidity, frost, dew, snow, fog, etc., which will cause short circuit and leakage and discharge of circuit; generally, the space in the cabinet is narrow, the equipment operates under high load for a long time, and the ambient temperature and electrical contact temperature are easy to be on the high side. If the monitoring and treatment are not timely, it is easy to cause fire or explosion accidents, which seriously affects the stability and safety of the BTS [22].

At present, with the development of power IoT technology, the fault diagnosis model is established based on the big data from BTS's on-line monitoring, the historical operation data of BTS is analyzed and mined, and the real-time risk assessment of operation state is carried out by using artificial intelligence methods such as machine learning, so as to discover the weak links in time and realize the transform from diagnosis based on traditional sensor to intelligent system. So, it has great significance to ensure the reliable operation of the BTS.

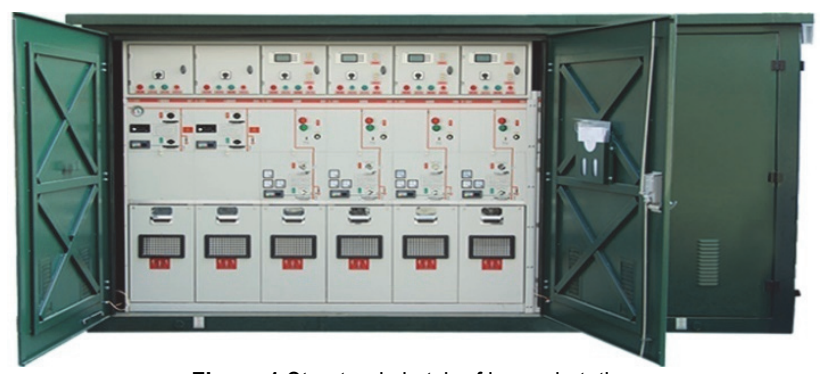

Figure 1 Structural sketch of box substation

Therefore, the first step is to establish the BTS's online monitoring fault diagnosis system framework as shown in Fig. 2. According to the typical three-tier architecture of IoT application, it is composed of perception layer, transport layer and application layer. The perception layer mainly solves the problem of information perception and collection, which is the core infrastructure; the transport layer mainly carries out reliable long-distance transmission of information; the application layer is used to support the platform and application services, which mainly support information collaboration, sharing and interworking.

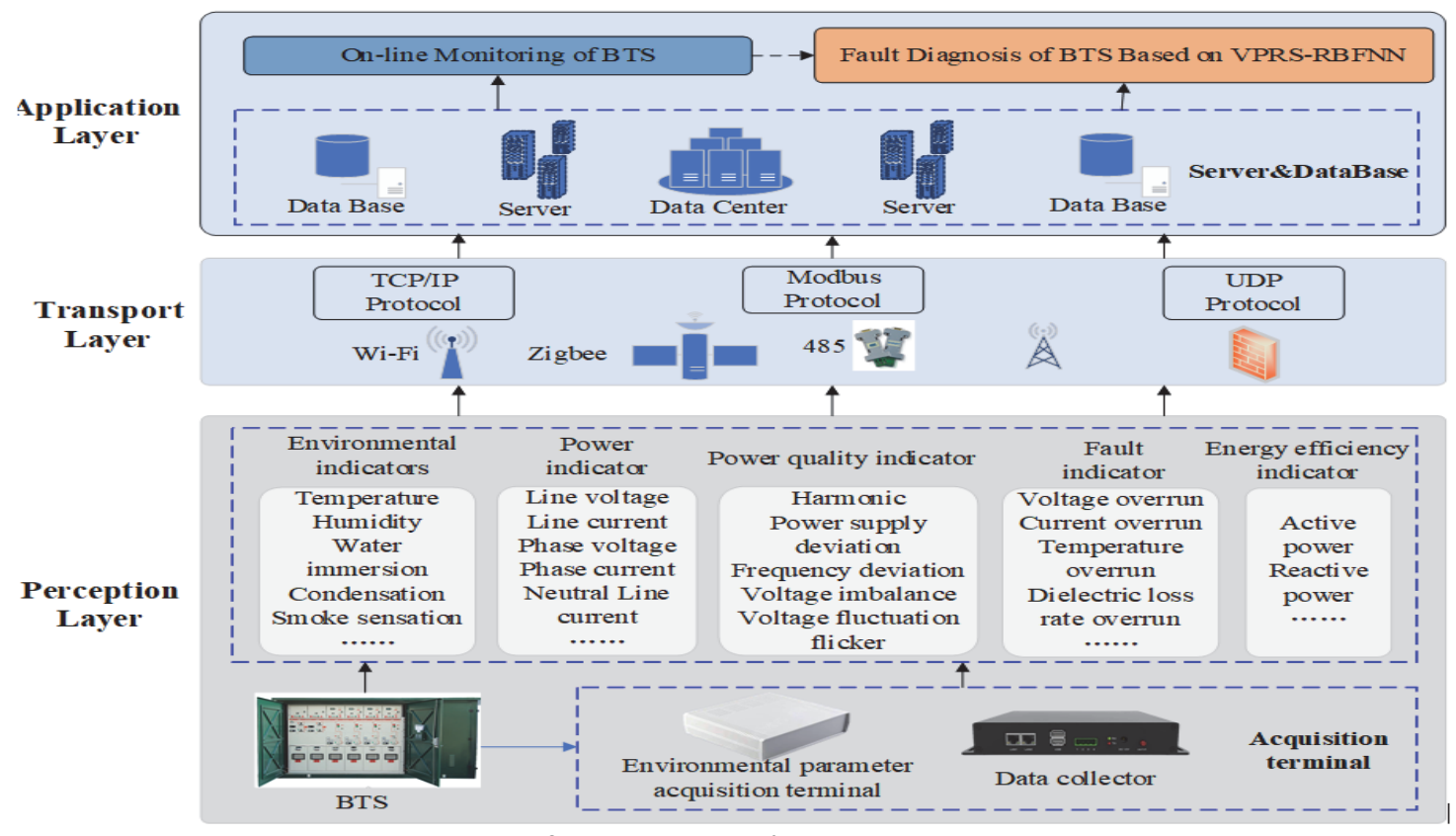

Figure 2 Systematic overview of the proposed approach

\subsection{Perception Layer}

The perception layer is designed with temperature and humidity controller, harmonic meter, YZ80 multi-function instrument, KY-8180A microcomputer transformer protection intelligent monitoring unit, smart sensors as the device for collecting operational data of box-type substation. The collected data includes different types, such as temperature and humidity, phase voltage, phase current, active power, reactive power, harmonic factor, and insulation factor. These data are divided into different indicators such as environment, electrical, power quality, energy efficiency, and fault. In order to properly collect the 
above monitoring data, the sensor deployment information is shown in Tab. 1.

Table 1 Sensor deployment table

\begin{tabular}{|c|c|c|c|c|}
\hline $\begin{array}{c}\text { Whole machine of } \\
\text { BTS }\end{array}$ & $\begin{array}{c}\text { High-voltage incoming } \\
\text { cabinet }\end{array}$ & Transformer chamber & Low-voltage incoming cabinet & Low-voltage outcoming cabinet \\
\hline $\begin{array}{c}\text { Water immersion } \\
\text { sensor }\end{array}$ & Integrated protector & Cable temperature sensor & Harmonic Meter & Cable temperature controller \\
\hline Entrance guard sensor & Multi-function meter & Temperature sensor & ARTU controller & Six multifunction meters \\
\hline Smoking sensor & Temperature sensor & Smoking sensor & Cable temperature controller & Temperature sensor \\
\hline- & Humidity sensor & Condensation sensor & Temperature sensor & Humidity sensor \\
\hline- & Smoking sensor & - & Humidity sensor & Condensation sensor \\
\hline- & Condensation sensor & - & Condensation sensor \\
\hline
\end{tabular}

\subsection{Transport Layer}

The intelligent monitoring units and sensors designed by the perception layer adopt a combination of wired RS485 and wireless Zigbee and Wi-Fi to convert the original data into the data collector through the Modbus protocol for further analysis and processing. After the encapsulation of TCP/IP protocol, the data is transmitted to the server's database or data center via GPRS.

\subsection{Application Layer}

The application layer is usually rich in content. This framework only focuses on real-time online monitoring and fault diagnosis of the BTS. It consists of two parts: the real-time online monitoring and the fault diagnosis based on VPRS-RBFNN. The essence of BTS's real-time online monitoring is real-time collection and monitoring of operation data of BTS equipment system based on IoT technology. Through this, real-time collection and supervision of the operation parameters of the BTS equipment and its external environment information can be realized, which is the basis and data source for online diagnosis of BTS faults. The fault diagnosis of BTS based on VPRS-RBFNN is based on the real-time monitoring of box transformer operation information. The main process is to establish a fault diagnosis model between the key fault components and the fault characteristic parameters of the BTS. Based on the VPRS-RBFNN fault diagnosis algorithm, the model is trained by large amount of BTS's historical fault data, the failure modes are mined from the real-time data, and finally the fault diagnosis of the BTS can be realized.

\section{FAULT DIAGNOSIS BASED ON VPRS AND RBFNN}

In the IoT environment, the BTS's fault diagnosis changes from the original manual diagnosis mode to the online fault diagnosis, the fault diagnosis decision is made based on the data of the device characteristic parameters. As an important power distribution equipment, the BTS has many characteristic parameters, which have a nonlinear and complex relationship with each other and with the fault mechanism. Therefore, it is impossible to directly establish fault models from data.

\subsection{The BTS's Fault Diagnosis Process Based on VPRS and RBFNN}

Neural networks are often used to solve nonlinear problems [22]. Among them, RBFNN has the advantages of simple structure, strong nonlinear fitting ability, fast approaching and high robustness. Compared with traditional neural networks, it can better overcome the shortcomings of local minimum and slow convergence speed, and is widely used in fault diagnosis, pattern recognition and other fields [23-25]. The input characteristic parameters of the BTS are various and the number is large, which undoubtedly greatly increases the complexity of the topology structure of the RBFNN, which increases the training time of the fault diagnosis model and increases the difficulty of network convergence.

The Variable Precision Rough Set (VPRS) can be used as a strategy to solve the nonlinear correspondence problem. It can mine potential knowledge and laws from massive data without prior knowledge [26]. However, if it is used as the theoretical basis for the fault diagnosis model of the BTS, a perfect decision table is needed to obtain a fault rule with high credibility. In this case, the number of rules generated will be far greater than the rules given by experts. This is undoubtedly a huge problem [27].

Considering the complexity of RBFNN modelling and the knowledge of variable precision rough set with the advantages of knowledge reduction, the variable precision rough set can be combined with the RBFNN algorithm. The variable precision rough set knowledge reduction ability can be used to reduce the feature, in the other words, the number of parameters is reduced, the original sample of the RBFNN is subtracted, the redundant information is removed, the scale of the RBF network is simplified, the training time is reduced, so that the fault diagnosis model is more real-time, rapid and accurate.

The core of the VPRS-RBFNN algorithm is to use the variable precision rough set as the front-end processing system of the RBFNN, to quantitatively simplify large numbers of original samples and find the main characteristic parameters that lead to box change fault. Then, the information reduced from the variable precision rough set is input into the neural network for training, and the fault diagnosis model is formed; then the test data is brought into the fault model to test the feasibility of the model. By integrating the variable precision rough set and the radial basis neural network, we give the overall process of box fault diagnosis based on VPRS-RBFNN. As shown in Fig. 3, the specific steps can be summarized as follows: Step 1: Extract fault history data and establish an original decision table;

Step 2: Data preprocessing, processing the data in the original decision table;

Step 3: Discretization and simplification of the conditional data, forming a decision table after reduction; 
Step 4: The data in the decision table after simplification is brought into the RBFNN for training;

Step 5: Test the trained model with test data;

Step 6: Output the result.

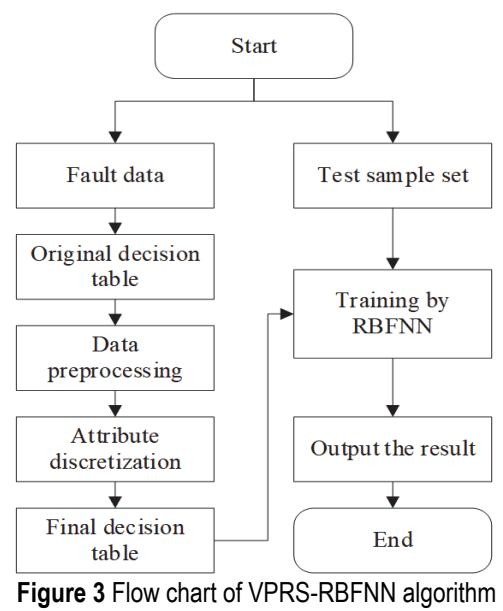

\subsection{Fault Diagnosis Algorithm Based on VPRS-RBFNN}

The realization of the algorithm based on VPRSRBFNN mainly includes the following aspects:

Step 1: Samples selection

The selection of samples should follow the principle of representativeness and compactness, and select common faults and faultless representative data from the characteristic parameter database of the BTS. The selected data is used as the original decision table of the variable precision rough set. In this decision table, the sample object is represented by $Y=\left\{y_{1}, y_{2}, \ldots, y_{i}, \ldots, y_{n}\right\}, n$ is the number of samples. The characteristic parameters are expressed as $X=\left\{x_{1}, x_{2}, \ldots, x_{j}, \ldots, x_{m}\right\}$ and $\mathrm{m}$ is the number of characteristic parameters. The fault type is expressed as $D$ $=\left\{d_{1}, d_{2}, \ldots, d_{\mathrm{k}}, \ldots, d_{h}\right\}$ and $\mathrm{h}$ is the number of fault types.

Step 2: Knowledge reduction.

Variable precision rough set can be expressed as a quadruple $S=<U, A, V, f>$, where $U=\left\{y_{1}, y_{2}, \ldots, y_{n}\right\}$ is the universe, which is a finite set consisting of sample object $y_{i}(i=1,2, \ldots, n) ; A=C \cup D, C \cap D=\varnothing, C=\left\{a_{1}, a_{2}, \ldots, a_{p}\right\}$ is a finite set of conditional attributes; $D$ is a set of decision attributes, $f$ is an information function; $f: U \times A \rightarrow V$ is a single mapping, in other words $\forall a \in A, y \in U, f(y, a) \in V_{a}, f(y$, $a$ ) is the information value of each attribute of each object in $U$. Knowledge reduction is to reduce the characteristic parameters. First, we need to build the original decision table (that is the universe) by using n samples in the set $Y$. Then, m characteristic parameters in set $X$ are taken as the conditional attribute set of decision table, that is, attribute set $C$. Fault type set $D$ is the decision attribute set of decision table.

The detailed process of step 2 is as follows:

Step 2.1: Standardizing the condition attribute in the original decision table;

Standardization uses the Z-core normalization method, as shown in Eq. (1):

$x_{j}=\frac{x_{j}-E\left(x_{j}\right)}{D\left(x_{j}\right)}, j=1,2, \ldots, m$ where $E\left(x_{j}\right)$ is the mean value of the characteristic parameter $x_{j}$ in the original sample set, and $D\left(x_{j}\right)$ is the standard deviation corresponding to the characteristic variable $x_{j}$.

Step 2.2: Discretizing the data of condition and decision attribute of the original decision table, divide the range of continuous attributes into several sub-intervals to obtain the discrete table $S^{*}$;

Step 2.3: Making the attribute kernel set CORE empty, $0.5<\beta \leq 1$ ( $\beta$ represents the allowable range of classification error rate), $i=1$; repeating execute step 2.4 to step 2.6 for $m$ conditional attributes;

Step 2.4: For the equivalent relation ind in the discrete table $S^{\prime}$ obtained in step 2.2, calculating the relative correct classification rate $P$ according to Eq. (2), comparing whether $P$ is greater than $\beta$, if so, using Eq. (3) to calculate the positive region $\mathrm{POS}_{\beta} \mathrm{C}$ :

$$
\begin{gathered}
P(C, D)=\left\{\begin{array}{cc}
\frac{|C \cap D|}{|C|} & |C|>0 \\
1 & |C|=0
\end{array}\right\} \\
\operatorname{POS}_{\beta} C=\underline{R} C_{\beta}=\bigcup\{C: P(C, D) \geq \beta\}
\end{gathered}
$$

Step 2.5: Using Eq. (4) to calculate the dependence $\lambda(C, D, \beta)$ of condition attribute on decision attribute:

$\lambda(C, D, \beta)=\frac{\left|\operatorname{POS}_{\beta}(C, D, \beta)\right|}{|U|}$

If the dependence $\lambda\left(C_{i}, D_{i}, \beta\right)$ of a single attribute $i$ is equal to $\lambda(C, D, \beta)$, the attribute is redundant and deleted; otherwise, using Eq. (5) to calculate the importance $\operatorname{SIG}(C,\{i\})$, when $\operatorname{SIG}(C,\{i\}) \neq 0$, taking this attribute as one of the attribute CORE, namely CORE $=\left\{C_{i},\right\}$; otherwise, this attribute is a non-attribute CORE, let $i=i+$ 1 ;

$\operatorname{SIG}(C,\{i\})=\lambda(C,\{i\}, \beta)+\lambda(\{i\}, D, \beta)$

Step 2.6: Judging whether the loop is terminating; if $I$ $>m$, terminating the cycle and executing step 2.7; otherwise, return to step 2.3:

Step 2.7: Obtaining attribute core set CORE and forming attribute reduction table.

Step 3: Training the sample set

Part of the data after reduction in the decision table is selected as the training sample, and a RBFNN topology with $Y_{i}^{\prime}$ input vectors, $X_{j}^{\prime}$ hidden units and $D_{k}$ output units is designed. According to the algorithm flow of RBFNN, the sample set is trained. The specific steps are as follows:

Step 3.1: Initializing parameters. Given the initial learning rate $\eta$, momentum factor $\alpha, \eta \in(0,1), \alpha \in(0,1)$; the termination precision $\varepsilon$ :

Step 3.2: Determining input vector $\boldsymbol{X}$, output vector $\boldsymbol{Y}$, and desired output vector $\boldsymbol{O}, \boldsymbol{X}=\left[x_{1}, x_{2}, \ldots, x_{n}\right]^{\mathrm{T}}, \boldsymbol{Y}=\left[y_{1}\right.$, $\left.y_{2}, \ldots, y_{q}\right]^{\mathrm{T}}, \boldsymbol{O}=\left[o_{1}, o_{2}, \ldots, o_{q}\right]^{\mathrm{T}}$; 
Step 3.3: Initializing the connection weight from the hidden layer to the output layer. Use Eq. (6) to initialize the weight, and get $W_{k}=\left[w_{k 1}, w_{k 2}, \ldots, w_{k n}\right]^{\mathrm{T}},(k=1,2, \ldots, q)$;

$$
W_{k j}=\min k+j \frac{\max k-\min k}{q+1}
$$

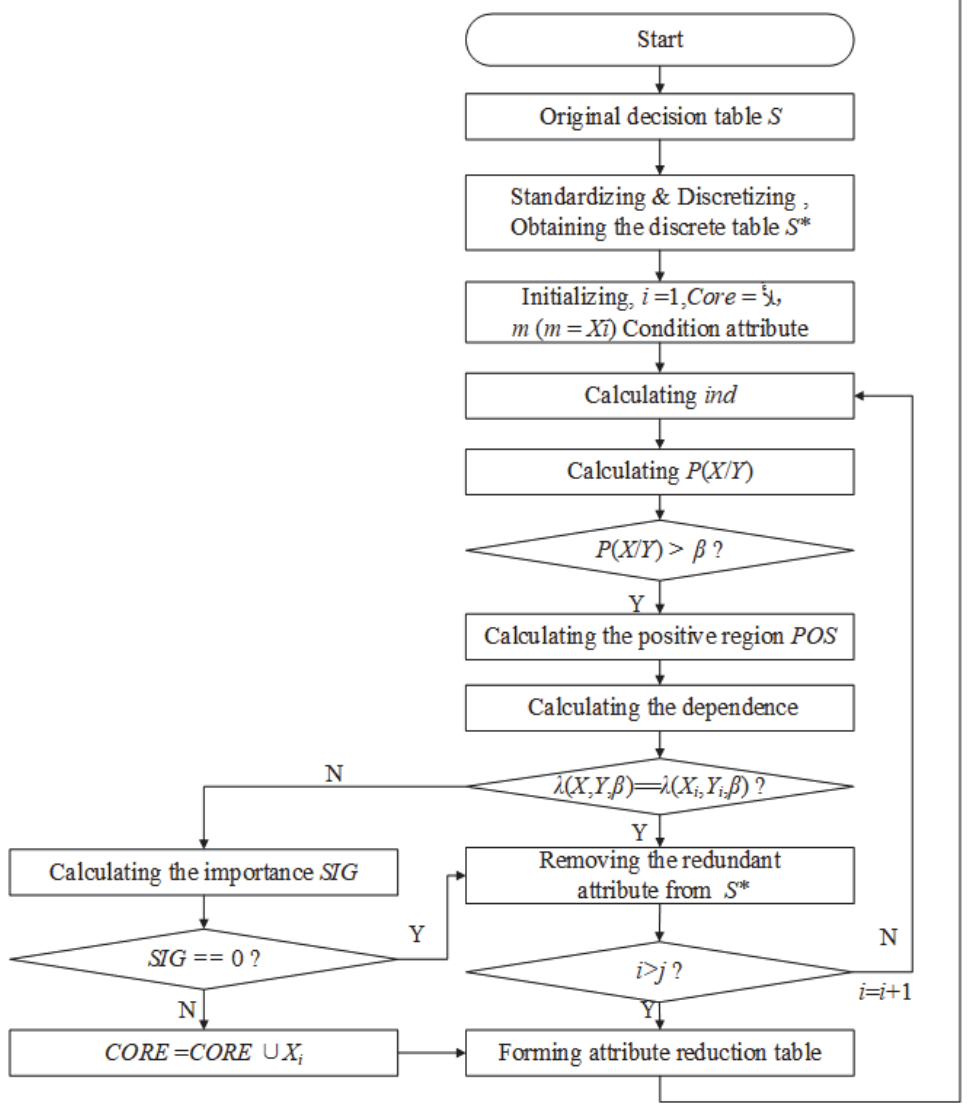

Figure 4 Algorithm block diagram of VPRS-RBFNN for BTS

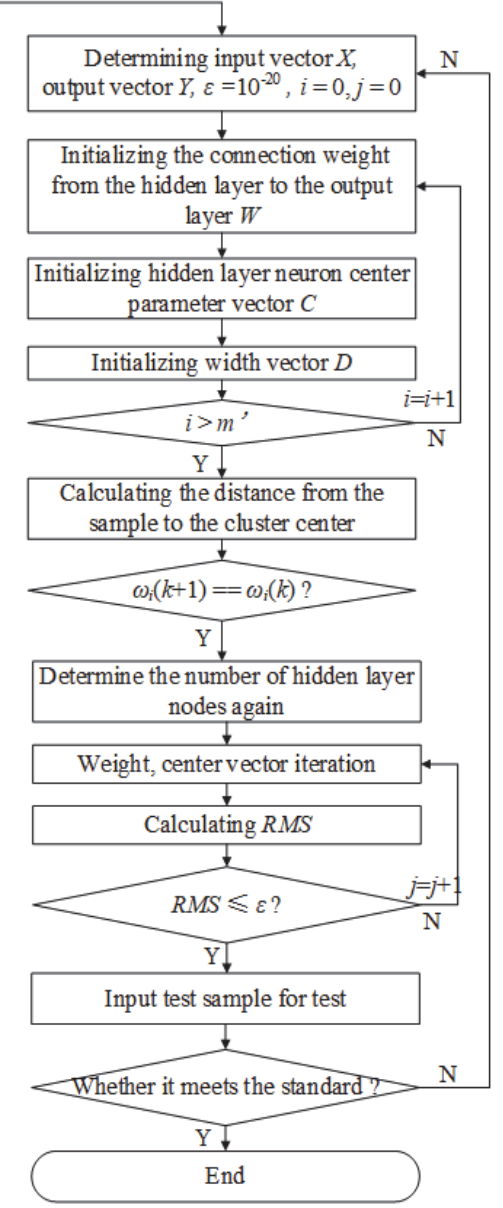

Step3.4: Initializing hidden layer neuron center parameter vector, $\boldsymbol{C}_{j i}=\left[c_{j 1}, c_{j 2}, \ldots, c_{j 3}\right]^{\mathrm{T},}(j=1,2, \ldots, p)$, as shown in Eq. (7):

$c_{j i}=\min i+\frac{\max i-\min i}{2 p}+(j-1) \frac{\max i-\min i}{p}$

Step3.5: Initializing width vector, from Eq. (8), $\boldsymbol{D}_{\boldsymbol{j} i}=$ $\left[d_{j 1}, d_{j 2}, \ldots, d_{j 3}\right]^{\mathrm{T}}$;

$$
d_{i}=d_{f} \sqrt{\frac{1}{N} \sum_{k=1}^{N}\left(x_{i}-c_{i}\right)}
$$

Step3.6: Calculating the distance from the sample to the cluster center;

Step3.7: According to Eq. (8), Eq. (9), Eq. (10), the weight, center point and center width parameters are calculated iteratively;

$$
\begin{aligned}
& c_{i}(n+1)=c_{i}(n)-\eta \frac{\partial \xi(n)}{\partial c_{i}(n)} \\
& w_{i}(n+1)=c_{i}(n)-\frac{\partial \xi(n)}{\partial w_{i}(n)}
\end{aligned}
$$

Step 3.8: Calculating root mean square error of output $R M S$, if $R M S \leq \varepsilon$, turn to step 2.7, otherwise, finishing the training.

$$
R M S=\sqrt{\sum_{i=1}^{n} \sum_{k=1}^{q}\left(O_{l k}-y_{l k}\right)^{2}}
$$

Step 4: Testing the sample set

The remaining data in the decision table is selected as the test sample, and the RBFNN training results are compared with the test sample to obtain the fault diagnosis accuracy of the RBF fault diagnosis model.

According to the content of the algorithm, the specific steps of the VPRS-RBFNN fault diagnosis algorithm are summarized in Fig. 4.

\section{EXAMPLE VERIFICATION AND RESULTS ANALYSIS}

We select six key fault components from BTS's equipment list, which are respectively dry-type transformer, high-voltage circuit breaker, capacitor arrester, low-voltage outlet breaker, low-voltage incoming circuit breaker, high-voltage lightning arrester; then, the 24 characteristic parameters shown in Tab. 2 of the six key 
components are selected from BTS's historical data as the fault data source.

Based on VPRS and RBFNN, firstly, we establish a fault diagnosis model between six key fault components and 24 characteristic parameters, and then the fault diagnosis model is trained by fault characteristic parameter data, finally, the fault type of the BTS can be inferred by inputting parameter's real-time data.

The establishment process of fault diagnosis model is as follows:

(1) Construct the original decision table
From the fault historical database of BTS, 30 groups of data are extracted to establish the original decision table. Using $\mathrm{X}_{j}(j=1 \sim 24)$ to represent 24 condition attributes; and $\mathrm{Y}_{\mathrm{i}}(i=1 \sim 30)$ to indicate selected data; $D_{k}(k=1 \sim 7)$ indicates the fault type, the specific meanings are: D1: no fault; D2: dry transformer fault; D3: high voltage breaker fault; D4: capacitor arrester fault; D5: low voltage outlet breaker fault; D6: Low voltage incoming circuit breaker failure; D7: High voltage lightning arrester failure. We select the data to obtain the original decision table as shown in Tab. 3.

Table 2 Fault characteristic parameter of BTS

\begin{tabular}{|c|c|c|c|c|c|c|c|}
\hline $\begin{array}{c}\text { Serial } \\
\text { number }\end{array}$ & $\begin{array}{l}\text { Characteristic } \\
\text { parameter }\end{array}$ & $\begin{array}{c}\text { Serial } \\
\text { number }\end{array}$ & $\begin{array}{l}\text { Characteristic } \\
\text { parameter }\end{array}$ & $\begin{array}{c}\text { Serial } \\
\text { number }\end{array}$ & Characteristic parameter & $\begin{array}{c}\text { Serial } \\
\text { number }\end{array}$ & Characteristic parameter \\
\hline 1 & temperature & 7 & partialdischarge & 13 & highvoltage & 19 & bus temperature \\
\hline 2 & humidity & 8 & dielectriclossratio & 14 & highvoltagecurrent & 20 & neutral line current \\
\hline 3 & water immersion & 9 & windingabsorptionratio & 15 & $\begin{array}{l}\text { Lowvoltageincoming line } \\
\text { voltage }\end{array}$ & 21 & actionrejectioninformation \\
\hline 4 & smoke detector & 10 & coregroundcurrent & 16 & Lowvoltageoutgoingvoltage & 22 & tripinformation \\
\hline 5 & dewing & 11 & ironcore temperature & 17 & Lowvoltageincomingcurrent & 23 & $\begin{array}{l}\text { contact temperature } \\
\text { ofcircuitbreaker }\end{array}$ \\
\hline 6 & contactresistance & 12 & frequency & 18 & Lowvoltageoutgoingcurrent & 24 & $\begin{array}{c}\text { current at } \\
\text { bothendsofcircuitbreaker }\end{array}$ \\
\hline
\end{tabular}

Table 3 Original decision table of BTS

\begin{tabular}{|c|c|c|c|c|c|c|c|c|c|c|c|c|c|c|c|c|c|c|c|c|c|c|c|c|c|}
\hline Object & X1 & $\mathrm{X} 2$ & X3 & X4 & X5 & X6 & X7 & X8 & X9 & X10 & X11 & X12 & X13 & X14 & X15 & X16 & X17 & X18 & X19 & X20 & X21 & $\mathrm{X} 22$ & $\mathrm{X} 23$ & X24 & \begin{tabular}{|c}
$\begin{array}{c}\text { Failure } \\
\text { mode }\end{array}$ \\
\end{tabular} \\
\hline Y1 & 16 & 32 & 25 & 0.15 & 3 & 111 & 60 & 0.32 & 1.41 & 0 & 50 & 50.1 & \begin{tabular}{|l|}
6.64 \\
\end{tabular} & 2.45 & 224 & 221 & 1.5 & 13 & 54 & 0 & 0 & 0 & 44 & 21 & D1 \\
\hline Y2 & 25 & & & 0 & 11 & 234 & 21 & & & 0.02 & & & & & 223 & & .2 & & & 1.4 & & & 50 & 23 & D1 \\
\hline Y3 & 35 & 23 & 7 & 0.03 & 2 & 336 & 111 & 57 & 28 & 70 & 52 & .1 & \begin{tabular}{|l|}
8.89 \\
\end{tabular} & 1.28 & 225 & 222 & 14 & 20 & & & & & 4 & 20 & D2 \\
\hline Y4 & 40 & 15 & 2 & 0.60 & 0 & 517 & 735 & 0.88 & 1.55 & 0.51 & 44 & 0.1 & 6.77 & 2.56 & 221 & 221 & 1.4 & 24 & 40 & 0 & & & 47 & 25 & D2 \\
\hline Y5 & 29 & 31 & 8 & 0.23 & 4 & 275 & 838 & 0.95 & 1.40 & 0.04 & 50 & 50.4 & 6.23 & 2.48 & 224 & 222 & 1.3 & 18 & 43 & 1.8 & & 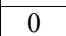 & 30 & 18 & D2 \\
\hline Y6 & 34 & 0 & 1 & 0.11 & 1 & 212 & 95 & 0.94 & 35 & 20 & 42 & 50.2 & 7.58 & \begin{tabular}{|l|}
0.89 \\
\end{tabular} & 222 & 221 & 1.5 & 32 & 55 & 2.5 & & & 32 & 24 & D2 \\
\hline Y7 & 31 & & 33 & 04 & 94 & 654 & 234 & 20 & .00 & 30 & 66 & & \begin{tabular}{|l|}
6.11 \\
\end{tabular} & 2.89 & 222 & 224 & 1.7 & 42 & 66 & & & & 41 & 37 & $\mathrm{D} 2$ \\
\hline Y8 & 37 & 11 & & 35 & 0 & 156 & 18 & & 25 & & 34 & & 34 & 0.22 & 220 & 220 & 1.6 & & & & & & & 10 & D3 \\
\hline Y9 & 29 & 33 & 4 & 0.55 & 1 & 333 & 123 & 0.55 & 1.30 & 0.22 & 41 & 50.3 & 88 & 0.14 & 221 & 222 & 1.5 & 42 & 3 & 0 & & ( & & 19 & D3 \\
\hline Y10 & 32 & & 3 & 0.32 & 1 & 96 & 566 & 1.23 & 1.10 & 0.11 & 34 & 49.9 & 6.88 & 1.56 & 221 & 223 & 1.7 & 36 & 41 & 0.2 & 0 & & 62 & 28 & D3 \\
\hline Y11 & 45 & 2 & 21 & 0 & 13 & 38 & 936 & 34 & 0.89 & .27 & 35 & & \begin{tabular}{|l|}
9.75 \\
\end{tabular} & 0.11 & 223 & 221 & 1.8 & 44 & 4 & & & & & 15 & D3 \\
\hline Y12 & 36 & & 0 & 0.11 & 0 & 75 & 123 & 0.48 & 0.44 & 0.03 & 31 & 50.1 & 6.34 & 2.35 & 220 & 220 & 1.9 & & & & & & & 0 & D3 \\
\hline Y13 & 29 & 9 & 56 & 33 & 96 & 58 & 35 & 36 & 15 & .01 & 30 & 51.2 & 6.21 & 2.47 & 221 & 222 & 1.4 & 25 & 38 & & & & 3 & 25 & D4 \\
\hline Y14 & 30 & 5 & 8 & 0.17 & 94 & 68 & 48 & 0.38 & 0.21 & 0.02 & 35 & 51.0 & 6.23 & 2.46 & 220 & 221 & 1.5 & 24 & 40 & & & & 3 & 21 & D4 \\
\hline Y15 & 32 & & & 22 & 90 & 53 & 88 & 0.12 & & .05 & 36 & & 6.74 & 2.45 & 220 & 221 & 1.6 & 30 & 3 & 3 & & & 3 & 20 & D4 \\
\hline Y16 & 34 & 91 & 1 & 0.12 & 91 & 75 & 74 & 0.13 & 40 & 0.04 & 37 & & 6.21 & 2.12 & 221 & 223 & 1.7 & 25 & 48 & & & & 3 & 22 & D4 \\
\hline Y17 & 31 & 93 & 53 & 0 & 92 & 88 & 100 & 0 & 1.56 & 0.05 & 34 & 9 & 6.37 & 2.28 & 222 & 221 & 1.8 & 27 & 3 & & & & 3 & 26 & D4 \\
\hline Y18 & 34 & 14 & 10 & 0.01 & 2 & 99 & 121 & 0.08 & 0.11 & 0.01 & 38 & 49.1 & 6.31 & 2.15 & 224 & 258 & 1.4 & & 6 & & & & 50 & 24 & D5 \\
\hline Y19 & 35 & 20 & 8 & 0.34 & 1 & 114 & 95 & 0.06 & 1.34 & 0.08 & 37 & 49.2 & 6.22 & 2.43 & 221 & 274 & 1.5 & & 5 & & & & 52 & 12 & D5 \\
\hline $\mathrm{Y} 20$ & 36 & & 4 & & 4 & 88 & 252 & & & & 37 & & & 2.21 & 223 & 293 & 1. & & & & & & & & D5 \\
\hline $\mathrm{Y} 21$ & 37 & 3 & 6 & 0.55 & 2 & 98 & 114 & 0 & 1.23 & .03 & 38 & & 6.28 & 2.23 & 220 & 288 & 1. & & & & & & & 21 & D5 \\
\hline Y22 & 31 & 1 & 1 & 0.47 & 1 & 109 & 103 & 0.01 & 1.24 & 0.05 & 38 & 50.1 & 6.12 & 2.24 & 221 & 269 & 1.8 & 6 & 58 & 18 & 0 & 1 & 58 & 0 & D5 \\
\hline Y23 & 36 & 1 & 1 & 0.88 & 1 & 86 & 103 & 0.64 & 1.52 & 0.01 & 40 & 50.2 & 6.22 & 2.55 & 288 & 221 & 0.1 & 21 & 38 & 2 & 0 & 1 & 40 & 24 & D6 \\
\hline Y24 & 37 & 2 & 2 & 0.4 & 2 & 75 & \begin{tabular}{|l|}
98 \\
\end{tabular} & 0.7 & 1.19 & 0.02 & 41 & 49 & 6.32 & 2.26 & 276 & 220 & 0.5 & 2 ? & 3 & 12 & & & 4 & 26 & D6 \\
\hline Y25 & 36 & & 2 & & 2 & 6 & 56 & & & .01 & 38 & & 6.16 & 2.24 & 294 & 223 & 0.1 & & & & & & & 31 & D6 \\
\hline Y26 & 39 & 3 & 3 & & 3 & 3 & 38 & & & & 39 & & & 2.55 & 265 & 224 & 0.3 & 27 & 3 & & & & 40 & 0 & D6 \\
\hline Y27 & 40 & 9 & 5 & 80 & 91 & 88 & 678 & 0 & 43 & 02 & 40 & & & 2.38 & 220 & 220 & 1.8 & 29 & 39 & 41 & 0 & 0 & 38 & 28 & D7 \\
\hline Y28 & 41 & 96 & 49 & 86 & 90 & 56 & 742 & 0.66 & 0.58 & 0.06 & 38 & 50.7 & 6.47 & 2.64 & 221 & 223 & 1.7 & 26 & 42 & & 0 & 0 & 36 & 26 & D7 \\
\hline Y29 & 42 & 92 & 62 & 0.64 & 90 & 39 & 655 & 0.5 & 1.1 & 0.07 & 37 & 49 & 6.66 & 2.33 & 223 & 224 & 1.6 & 2 & 4 & & & & 39 & 32 & D7 \\
\hline Y30 & 40 & 93 & 53 & 0.52 & 92 & 47 & 831 & 0.72 & 0.62 & 0.08 & 39 & 50.3 & 6.52 & \begin{tabular}{|l|}
2.49 \\
\end{tabular} & 220 & 221 & 1.5 & 31 & 42 & 38 & & & 40 & 12 & D7 \\
\hline
\end{tabular}

(2) Standardization of original decision table

Due to the different data dimensions, all data are normalized through the Z-core method according to Eq. (1), so that the 24 characteristic parameters which can standardly measure the importance of the observed object are under the same dimension. The results obtained are shown in Tab. 4.

(3) Discretization

Using the equal-frequency discrete method, the discrete frequency is 4 . The discrete result obtained by the equal-frequency discrete method can set a breakpoint for each attribute by calculating the number of attribute values included, so that each interval includes the same number of objects, and re-obtaining a simpler discrete result representation. The equal-frequency discrete representation is shown in Tab. 5 .

The discretized table is converted according to this representation method to obtain the final discrete result as shown in Tab. 6. 


\begin{tabular}{|c|c|c|c|c|c|c|c|c|c|}
\hline Object & $\mathrm{X} 1$ & $\mathrm{X} 2$ & $\mathrm{X} 3$ & $\mathrm{X} 4$ & $\mathrm{X} 5$ & . & X23 & X24 & Failure Type \\
\hline Y1 & -3.269 & -0.500 & 0.158 & -0.728 & -0.698 & $\ldots$ & 0.144 & 0.107 & D1 \\
\hline Y2 & -1.661 & 0.005 & -0.394 & -1.294 & -0.509 & $\ldots$ & 0.719 & 0.329 & D1 \\
\hline & & & & & & $\cdots$ & & & \\
\hline Y30 & 1.018 & 1.312 & 1.447 & 0.670 & 1.411 & $\ldots$ & -0.240 & -0.890 & D7 \\
\hline
\end{tabular}

Table 5 Equifrequency discrete representation (Take attribute $\mathrm{X} 1$ as an example)

\begin{tabular}{|c|c|c|}
\hline Intervals & Expression & Frequency of occurrence \\
\hline$[*,-0.50013)$ & 0 & $30 \%$ \\
\hline$[-0.50013,0.21434)$ & 1 & $23.3 \%$ \\
\hline$[0.21434,0.66089)$ & 2 & $23.3 \%$ \\
\hline$[0.66089, *)$ & 3 & $23.3 \%$ \\
\hline
\end{tabular}

Table 6 Final results of discretization of BTS

\begin{tabular}{|c|c|c|c|c|c|c|c|c|c|c|c|c|c|c|c|c|c|c|c|c|c|c|c|c|c|}
\hline Object & $\mathrm{X} 1$ & $\mathrm{X} 2$ & X3 & $\mathrm{X} 4$ & X5 & X6 & X7 & $\mathrm{X} 8$ & X9 & X10 & X11 & X12 & X13 & X14 & $\mathrm{X} 15$ & X16 & X17 & $\mathrm{X} 18$ & X19 & X20 & X21 & X22 & X23 & X24 & $\begin{array}{c}\text { Failure } \\
\text { mode }\end{array}$ \\
\hline Y1 & 0 & 2 & 2 & 1 & 1 & 2 & 0 & 1 & 2 & 0 & 3 & 1 & 2 & 2 & 3 & 1 & 1 & 0 & 3 & 0 & 0 & 0 & 2 & 1 & D1 \\
\hline Y2 & 0 & 2 & 2 & 0 & 2 & 3 & 0 & 1 & 3 & 1 & 0 & 0 & 2 & 2 & 2 & 0 & 0 & 0 & 2 & 1 & 0 & 0 & 2 & 2 & D1 \\
\hline Y3 & 1 & 1 & 1 & 0 & 1 & 3 & 2 & 2 & 2 & 3 & 3 & 1 & 3 & 0 & 3 & 2 & 0 & 1 & 2 & 0 & 0 & 0 & 0 & 1 & D2 \\
\hline Y4 & 3 & 0 & 0 & 3 & 0 & 3 & 3 & 3 & 3 & 3 & 3 & 1 & 3 & 3 & 1 & 1 & 0 & 1 & 1 & 0 & 0 & 0 & 2 & 2 & D2 \\
\hline Y5 & 0 & 1 & 1 & 1 & 2 & 3 & 3 & 3 & 2 & 1 & 3 & 2 & 1 & 3 & 3 & 2 & 0 & 0 & 2 & 1 & 0 & 0 & 0 & 1 & D2 \\
\hline Y6 & 1 & 0 & 0 & 0 & 0 & 3 & 1 & 3 & 2 & 3 & 3 & 2 & 3 & 0 & 2 & 1 & 1 & 3 & 3 & 1 & 0 & 0 & 0 & 2 & D2 \\
\hline Y7 & 0 & 2 & 2 & 0 & 3 & 3 & 2 & 3 & 3 & 3 & 3 & 1 & 0 & 3 & 2 & 3 & 2 & 3 & 3 & 1 & 0 & 0 & 2 & 3 & D2 \\
\hline Y8 & 2 & 0 & 2 & 2 & 0 & 2 & 0 & 0 & 1 & 0 & 0 & 0 & 3 & 0 & 0 & 0 & 2 & 3 & 1 & 0 & 0 & 1 & 3 & 0 & D3 \\
\hline Y9 & 0 & 2 & 1 & 2 & 0 & 3 & 2 & 2 & 2 & 3 & 3 & 2 & 3 & 0 & 1 & 2 & 1 & 3 & 0 & 0 & 1 & 0 & 0 & 1 & D3 \\
\hline Y10 & 1 & 0 & 0 & 2 & 0 & 2 & 2 & 3 & 1 & 3 & 0 & 0 & 3 & 0 & 1 & 2 & 2 & 3 & 1 & 0 & 0 & 1 & 3 & 3 & D3 \\
\hline Y11 & 3 & 2 & 2 & 0 & 2 & 0 & 3 & 3 & 0 & 3 & 0 & 1 & 3 & 0 & 2 & 1 & 3 & 3 & 2 & 0 & 0 & 1 & 3 & 0 & D3 \\
\hline Y12 & 2 & 1 & 0 & 0 & 0 & 1 & 2 & 2 & 0 & 1 & 0 & 1 & 1 & 2 & 0 & 0 & 3 & 2 & 0 & 0 & 0 & 1 & 0 & 0 & D3 \\
\hline Y13 & 0 & 3 & 3 & 1 & 3 & 0 & 0 & 1 & 0 & 0 & 0 & 3 & 0 & 2 & 1 & 2 & 0 & 1 & 0 & 2 & 0 & 0 & 1 & 2 & D4 \\
\hline Y14 & 0 & 3 & 2 & 1 & 3 & 1 & 0 & 1 & 0 & 1 & 0 & 3 & 1 & 2 & 0 & 1 & 1 & 1 & 1 & 2 & 0 & 0 & 0 & 1 & D4 \\
\hline Y15 & 1 & 2 & 3 & 1 & 2 & 0 & 1 & 0 & 0 & 2 & 1 & 3 & 2 & 2 & 0 & 1 & 2 & 2 & 0 & 3 & 0 & 0 & 0 & 1 & D4 \\
\hline Y16 & 1 & 2 & 3 & 1 & 3 & 1 & 0 & 1 & 2 & 1 & 1 & 3 & 0 & 0 & 1 & 2 & 2 & 1 & 2 & 3 & 0 & 0 & 0 & 2 & D4 \\
\hline Y17 & 0 & 3 & 3 & 0 & 3 & 1 & 1 & 0 & 3 & 2 & 0 & 3 & 1 & 1 & 2 & 1 & 3 & 2 & 0 & 3 & 0 & 0 & 1 & 3 & D4 \\
\hline Y18 & 1 & 0 & 1 & 0 & 1 & 2 & 2 & 0 & 0 & 0 & 2 & 0 & 1 & 0 & 3 & 3 & 0 & 0 & 3 & 2 & 0 & 1 & 2 & 2 & D5 \\
\hline Y19 & 1 & 0 & 1 & 2 & 0 & 2 & 1 & 0 & 2 & 2 & 1 & 0 & 0 & 2 & 1 & 3 & 1 & 0 & 3 & 2 & 1 & 0 & 3 & 0 & D5 \\
\hline Y20 & 2 & 1 & 1 & 2 & 2 & 1 & 2 & 0 & 1 & 1 & 1 & 0 & 0 & 1 & 2 & 3 & 2 & 0 & 3 & 2 & 1 & 0 & 3 & 0 & D5 \\
\hline Y21 & 2 & 1 & 1 & 2 & 1 & 2 & 2 & 0 & 1 & 1 & 2 & 2 & 1 & 1 & 0 & 3 & 2 & 0 & 2 & 2 & 0 & 1 & 3 & 1 & D5 \\
\hline Y22 & 0 & 0 & 0 & 2 & 0 & 2 & 1 & 0 & 1 & 2 & 2 & 1 & 0 & 1 & 1 & 3 & 3 & 0 & 3 & 2 & 0 & 1 & 3 & 0 & D5 \\
\hline Y23 & 2 & 0 & 0 & 3 & 0 & 1 & 1 & 2 & 3 & 0 & 2 & 2 & 0 & 3 & 3 & 1 & 0 & 1 & 0 & 2 & 0 & 1 & 1 & 2 & D6 \\
\hline Y24 & 2 & 1 & 0 & 2 & 1 & 1 & 1 & 3 & 1 & 1 & 3 & 0 & 1 & 1 & 3 & 0 & 0 & 1 & 1 & 2 & 1 & 0 & 2 & 3 & D6 \\
\hline Y25 & 2 & 1 & 0 & 2 & 1 & 0 & 0 & 2 & 3 & 0 & 2 & 0 & 0 & 1 & 3 & 2 & 0 & 2 & 0 & 1 & 0 & 1 & 2 & 3 & D6 \\
\hline Y26 & 3 & 1 & 0 & 3 & 1 & 0 & 0 & 1 & 2 & 2 & 2 & 1 & 0 & 3 & 3 & 3 & 0 & 2 & 0 & 1 & 0 & 1 & 1 & 0 & D6 \\
\hline Y27 & 3 & 3 & 3 & 3 & 3 & 1 & 3 & 1 & 3 & 1 & 2 & 1 & 2 & 2 & 0 & 0 & 3 & 2 & 1 & 3 & 0 & 0 & 1 & 3 & D7 \\
\hline Y28 & 3 & 3 & 2 & 3 & 2 & 0 & 3 & 2 & 0 & 2 & 2 & 2 & 2 & 3 & 1 & 2 & 2 & 2 & 1 & 3 & 0 & 0 & 1 & 3 & D7 \\
\hline Y29 & 3 & 2 & 3 & 3 & 2 & 0 & 3 & 2 & 1 & 2 & 1 & 0 & 2 & 1 & 2 & 3 & 2 & 2 & 2 & 3 & 0 & 0 & 1 & 3 & D7 \\
\hline Y30 & 3 & 3 & 3 & 2 & 3 & 0 & 3 & 2 & 0 & 2 & 2 & 2 & 2 & 3 & 0 & 2 & 1 & 3 & 1 & 3 & 0 & 0 & 1 & 0 & D7 \\
\hline
\end{tabular}

(4) Attributes Reduction

When $\beta=0.7$, some of the attributes are subjected to variable precision rough set attributes reduction calculation. It can be seen from the result that the 24 conditional attributes of the BTS are reduced to 10 conditional attributes, which are $\mathrm{X} 1, \mathrm{X} 7, \mathrm{X} 8, \mathrm{X} 9, \mathrm{X} 10$, $\mathrm{X} 11, \mathrm{X} 12, \mathrm{X} 13, \mathrm{X} 14, \mathrm{X} 22$. These 10 characteristic parameters are the necessary conditional attributes, which are the basis for the fault diagnosis of the key components of the BTS.

(5) Establishment of RBFNN fault diagnosis model
For the convenience of programming, seven fault types of BTS are represented by $0 / 1$ code. After encoding, 1000000,0100000,0010000, 0001000,0000100,0000010, 0000001 respectively represent D1, D2, D3, D4, D5, D6, D7. At the same time, from the 30 final discretized original sample data, 20 samples $\{Y 1, Y 2, Y 3, Y 4, Y 5, Y 8, Y 9$, Y10, Y13, Y14, Y15, Y18, Y19, Y20, Y23, Y24, Y25, $\mathrm{Y} 27, \mathrm{Y} 28, \mathrm{Y} 29\}$ are selected as the training sample set, 10 samples $\{\mathrm{Y} 6, \mathrm{Y} 7, \mathrm{Y} 11, \mathrm{Y} 12, \mathrm{Y} 16, \mathrm{Y} 17, \mathrm{Y} 21, \mathrm{Y} 22, \mathrm{Y} 26$, $\mathrm{Y} 30\}$ are selected as the test sample set, as shown in Tab. 7.

Table 7 Test sample set

\begin{tabular}{|c|c|c|c|c|c|c|c|c|c|c|c|c|}
\hline Object & $\mathrm{X} 1$ & $\mathrm{X} 7$ & $\mathrm{X} 8$ & $\mathrm{X} 9$ & $\mathrm{X} 10$ & $\mathrm{X} 11$ & $\mathrm{X} 12$ & $\mathrm{X} 13$ & $\mathrm{X} 14$ & X22 & Failure mode & Ideal output \\
\hline $\mathrm{Y6}$ & 1 & 1 & 3 & 2 & 3 & 3 & 2 & 3 & 0 & 0 & D2 \\
\hline $\mathrm{Y} 7$ & 0 & 2 & 3 & 3 & 3 & 3 & 1 & 0 & 3 & 0 & 0100000 \\
\hline$\ldots \ldots$ & $\ldots$ & $\ldots$ & $\ldots$ & $\ldots$ & $\ldots$ & $\ldots$ & $\ldots$ & $\ldots$ & $\ldots$ & $\ldots \ldots$ & $\mathrm{D} 2$ \\
\hline $\mathrm{Y} 30$ & 3 & 3 & 2 & 0 & 2 & 2 & 2 & 2 & 3 & 0 & $\ldots$ & \\
\hline
\end{tabular}

(6) Analysis of diagnosis results

Ten characteristic parameters are used as input neurons, and seven failure modes are used as output neurons to establish a $10-20-7$ structure RBFNN. 20 groups of training data are sent to the model for iterative calculation, and the iterative error precision results are shown in Fig. 5.

It can be seen from the figure that the best model can be obtained by iterating 48 times, and the trained fault diagnosis model is closest to the actual situation. The test 
data is brought into the trained model to obtain the fault diagnosis results as shown in Tab. 8. The results in Tab. 8 show that, compared with 10 groups of actual fault types known in advance, there are 9 groups with the same results and 1 group with different results. That is, the diagnostic accuracy rate of the BTS's fault diagnosis model based on VPRS-RBFNN is $90 \%$, indicating that this model is feasible.

Table 8 Diagnostic results

\begin{tabular}{|c|c|c|c|c|c|c|c|c|c|}
\hline \multirow{2}{*}{$\begin{array}{c}\text { Object } \\
\text { Y6 }\end{array}$} & \multicolumn{7}{|c|}{ Model output } & \multirow{2}{*}{$\begin{array}{c}\text { Diagnostic results } \\
\mathrm{D} 2\end{array}$} & \multirow{2}{*}{$\begin{array}{c}\text { Actual resul } \\
\text { D2 }\end{array}$} \\
\hline & 0.19 & 1.32 & 0.11 & 0.33 & 0.03 & 0.01 & 0.06 & & \\
\hline Y7 & 0.01 & 1.94 & 0.57 & 0.31 & 0.23 & 0.03 & 0.02 & D2 & D2 \\
\hline Y11 & 0.09 & 0.23 & 1.81 & 0.25 & 0.35 & 0.44 & 0.03 & D3 & D3 \\
\hline Y12 & 1.89 & 0.04 & 1.47 & 0.34 & 0.28 & 0.43 & 0.05 & D2 & D3 \\
\hline Y16 & 0.23 & 0.06 & 0.04 & 2.24 & 0.12 & 0.32 & 0.04 & D4 & D4 \\
\hline Y17 & 0.22 & 0.06 & 0.07 & 2.24 & 0.04 & 0.34 & 0.05 & D4 & D4 \\
\hline Y21 & 0.2 & 0.03 & 0.06 & 0.33 & 1.82 & 0.36 & 0.03 & D5 & D5 \\
\hline Y22 & 0.19 & 0.01 & 0.02 & 0.34 & 1.85 & 0.37 & 0.03 & D5 & D5 \\
\hline Y26 & 0.23 & 0.01 & 0.03 & 0.33 & 0.47 & 1.82 & 0.03 & D6 & D6 \\
\hline Y30 & 0.18 & 0.02 & 0.04 & 0.32 & 0.42 & 0.36 & 1.77 & D7 & D7 \\
\hline
\end{tabular}

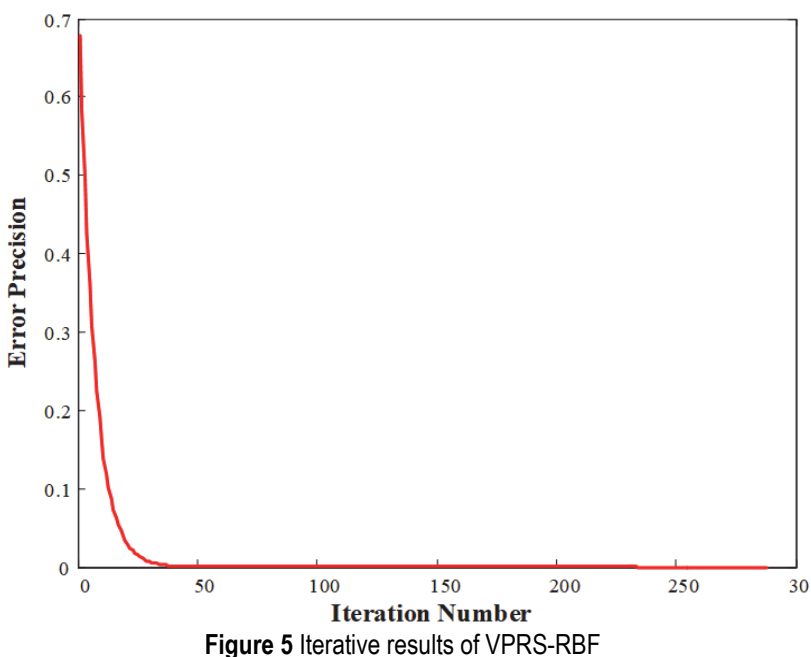

\section{CONCLUSIONS}

Using the IoT technology to fully perceive the operation state of BTS, and to quickly and intelligently diagnose the fault state can effectively improve the reliability of the BTS's operation. We construct a BTS's real-time online monitoring and fault diagnosis framework, and design the perception layer, transport layer and application layer in detail, which can meet the real-time monitoring requirements of the BTS's operation state; Based on the VPRS-RBFNN, fault diagnosis strategy is designed, the fault type and fault reason of BTS can be diagnosed in time. The accuracy of BTS's fault diagnosis is $90 \%$.

This strategy not only improves the management and maintenance level of the BTS, but also provides support for the BTS's maintenance plan. In order to realize the prewarning of the BTS's fault, our future work will focus on the BTS's fault early warning based on big data.

\section{Acknowledgments}

This research is supported by National Natural Science Foundation of China (No. 52005404) and funded by China Postdoctoral Science Foundation (No: 2020M673612XB).

\section{REFERENCE}

[1] Sahin, D., Gungor, V. C., \& Hancke, G. P. (2010). Wireless sensor networks for smart grid: Research challenges and potential applications. Smart Grid Communications and Networking, 265-278. https://doi.org/10.1017/CBO9781139013468.012

[2] Liu, J. M., Zhao, Z. Y., \& Ji, X. (2018). Research and application of Internet of things in power transmission and distribution system. Chinese Journal on Internet of Things, 2(1), 88-102.

[3] Roger, N. P., Teplaira, B. A., \& Salomé, N. E. (2020). Multi objective optimization of a power distribution system based on mixed integer programming. Journal Européen des SystèmesAutomatisés, 53(1), 39-46. https://doi.org/10.18280/jesa.530105

[4] Badugu, J., Obulesu, Y. P., \& Babu, C. S. (2019). Recharging methods of electric vehicles in residential distribution systems. Journal Européen des SystèmesAutomatisés, 52(6), 617-623. https://doi.org/10.18280/jesa.520609

[5] Rad, S. M. \& Nejad, M. B. (2019). New analog processing technique in multichannel neural signal recording with reduce data rate and reduce power consumption. Traitement du Signal, 36(2), 133-137. https://doi.org/10.18280/ts.360202

[6] Hu, J., Yin, L. Q., Li, Z., Guo, L. J., Duan, L., \& Zhang, Y. B. (2017). Fault diagnosis method of transmission and transformation equipment based on big data mining technology. High Voltage Engineering, 2017(11), 224-231.

[7] Feng, L. V., Du, H. L., Sun, H., Wang, Z. F., \& Yuan, L. I. (2008). Power Transformer Fault Diagnosis Based on Data Fusion. IFAC Proceedings Volumes, 41(2), 11013-11017. https://doi.org/10.3182/20080706-5-KR-1001.01865

[8] Lin, X., Xing, J., Chen, D., Li, Z., Rong, Z., Liu, Y., Liu, S. M., Su, S., Tong, N., \& Jing, R. (2018). A novel synchronous fault identification strategy of electronic transformer based on synergy of historical data. International Journal of Electrical Power \& Energy Systems, 103, 247-256. https://doi.org/10.1016/j.jiepes.2018.06.007

[9] Abu-Siada, A. \& Hmood, S. (2015). A new fuzzy logic approach to identify power transformer criticality using dissolved gas-in-oil analysis. International Journal of Electrical Power \& Energy Systems, 67, 401-408. https://doi.org/10.1016/j.jiepes.2014.12.017

[10] Velásquez, R. M. A. \& Lara, J. V. M. (2017). Principal components analysis and adaptive decision system based on fuzzy logic for power transformer. Fuzzy Information and Engineering, 9(4), 493-514. https://doi.org/10.1016/j.fiae.2017.12.005

[11] Malik, H. \& Jarial, R. K. (2012). Make use of DGA to carry out the transformer oil-immersed paper deterioration condition estimation with fuzzy-logic. Procedia Engineering, 30, 569-576.

https://doi.org/10.1016/j.proeng.2012.01.900 
[12] Chen, X., Liu, J., Huang, Y., \& Fu, B. (2012). Transformer fault diagnosis using improved artificial fish swarm with rough set algorithm. Gaodianya Jishu/High Voltage Engineering, 38(6), 1403-1409.

[13] Li, H., Zhang, Z. P., \& Zhang, Z. W. (2018). Fault diagnosis of transformer based on convolutional neural network. Journal of Henan Polytechnic University (Natural Science), 37(6), 118-123, 154.

[14] Islam, M. M., Lee, G., \& Hettiwatte, S. N. (2017). Application of a general regression neural network for health index calculation of power transformers. International Journal of Electrical Power \& Energy Systems, 93, 308-315. https://doi.org/10.1016/j.ijepes.2017.06.008

[15] Wang, L., Chen, Q., Gao, H., Ma, Z., Zhang, Y., \& He, D. (2018). Framework of fault trace for smart substation based on big data mining technology. Automation of Electric Power Systems, 42(3), 84-51.

[16] Mansour, M. M., Wahab, M. A., \& Soliman, W. M. (2013). Petri nets for fault diagnosis of large power generation station. Ain Shams Engineering Journal, 4(4), 831-842. https://doi.org/10.1016/j.asej.2013.04.006

[17] Meloni, A., Pegoraro, P. A., Atzori, L., Benigni, A., \& Sulis, S. (2018). Cloud-based IoT solution for state estimation in smart grids: Exploiting virtualization and edge-intelligence technologies. Computer Networks, 130, 156-165. https://doi.org/10.1016/j.comnet.2017.10.008

[18] Reka, S. S. \& Dragicevic, T. (2018). Future effectual role of energy delivery: A comprehensive review of Internet of Things and smart grid. Renewable and Sustainable Energy Reviews, 91, 90-108. https://doi.org/10.1016/j.rser.2018.03.089

[19] Gupta, A. K., Chakraborty, C., \& Gupta, B. (2019). Monitoring of epileptical patients using cloud-enabled health-IoT system. Traitement du Signal, 36(5), 425-431. https://doi.org/10.18280/ts.360507

[20] Li, X., Lin, C., \& Xu, X. P. (2019). A target tracking model for enterprise production monitoring system based on spatial information and appearance model. Traitement du Signal, 36(4), 369-375. https://doi.org/10.18280/ts.360410

[21] Zhang, Y., Liu, X. X., \& Shi, K. (2015). A novel method for intelligent fault diagnosis system of box-type substation. Information Technology, (4), 26-30.

[22] Shafieian, M., Zavar, M., \& Rahmanian, M. (2019). Simulation and control of surge phenomenon in centrifugal compressors. Traitement du Signal, 36(3), 259-264. https://doi.org/10.18280/ts.360309

[23] Fu, Q., Chen, T. F., \& Zhu, J. J. (2012). Transformer fault diagnosis using self-adaptive RBFNN algorithm. High Voltage Engineering, 38(6), 1368-1375.

[24] Rafik, D. \& Larbi, B. (2019). Autoregressive modeling based empirical mode decomposition (EMD) for epileptic seizures detection using EEG signals. Traitement du Signal, 36(3), 273-279. https://doi.org/10.18280/ts.360311

[25] Guo, Q., Yang, C., \& Tian, S. Q. (2020). Prediction of purchase intention among E-commerce platform users based on big data analysis. Revue d'IntelligenceArtificielle, 34(1), 95-100. https://doi.org/10.18280/ria.340113

[26] Ziarko, W. (1993). Variable precision rough set model. Journal of Computer and System Sciences, 46(1), 39-59. https://doi.org/10.1016/0022-0000(93)90048-2

[27] Huang, S. C. (2014). Limited and variable precision rough set model. Journal of Information and Computational Science, 11(10), 3493-3501. https://doi.org/10.12733/jics20103983

\section{Contact information:}

Erbao XU, PhD Candidate

(Corresponding author)

School of Mechanical and Precision Instrument Engineering,

Xi'an University of Technology,

Xi'an 710048, China

E-mail: baojams@126.com

Yan LI, PhD, Professor

School of Mechanical and Precision Instrument Engineering,

Xi'an University of Technology,

Xi'an 710048, China

E-mail: jyxy-ly@xaut.edu.cn

Mingshun YANG, PhD, Associate Professor

School of Mechanical and Precision Instrument Engineering,

Xi'an University of Technology,

Xi'an 710048, China

E-mail: yangmingshun@xaut.edu.cn

Renhao XIAO, Master Candidate

School of Mechanical and Precision Instrument Engineering, Xi'an University of Technology,

Xi'an 710048, China

E-mail: 842428103@qq.com

Hairui LIN, Master Candidate

School of Mechanical and Precision Instrument Engineering,

Xi'an University of Technology,

X'an 710048, China

E-mail: 2190221173@stu.xaut.edu.cn

Xinqin $\mathrm{GAO}, \mathrm{PhD}$, Professor

School of Mechanical and Precision Instrument Engineering,

Xi'an University of Technology.

Xi'an 710048, China

E-mail: gaoxinqin@xaut.edu.cn 